\title{
MICROBIOLOGICAL HYDROXYLATION OF STEROID IX. HYDROXYLATION OF STEROID BY SYNCEPHALASTRUM RACEMOSUM. (2)
}

\author{
TOSHINOBU ASAI, KO AIDA, TOKUJI TANAKA, EIJI OHKI, TAKEMASA \\ MATSUHISA, YOSHITO TAKEDA and TAIJI INUI \\ The Institute of Applied Microbiology and Research Laboratory of \\ Sanraku Distillers' Co., Inc. \\ Received for pub ication: July 4, 1959.
}

In previous studies on the oxidation of progesterone by Rhizopus fungus, the authors have reported that there are two kinds of Rhizopus species $(1,2)$, i.e. one that solely produces $11 \alpha$-hydroxyprogesterone and another which produces both $11 \alpha$-hydroxyprogesterone and $6 \beta$-, $11 \alpha$-dihydroxyprogesterone. It was also reported that a strain belonging to Syncephalastrum produces a dihydroxy progesterone and trihydroxy progesterone $(2,3)$ both of which cannot be found in the literature. Conditions of oxidation have also been described. Concerning these progesterones, the structure of dihydroxyprogesterone was determined by TsudA et al. (4) as $7 \alpha, 15 \beta$-dihydroxyprogesterone.

The present paper deals with the results obtained from investigations conducted on the taxonomical characteristics and identification of Syncephalastrum fungus, isolation and characteristics of trihydroxyprogesterone and oxidation of $11 \alpha$-hydroxyprogesterone, $6 \beta, 11 \alpha$-dihydroxyprogesterone, compound $\mathrm{S}$, hydrocortisone etc. by this strain.

\section{EXPERIMENTAL}

1. Identification of the used Strain, IAM-6801.

On the strain which was used in the previous report and described as Syncephalastrum sp., taxonomical studies were made. This strain was also used throughout present experiments.

(1) Diagnosis.

Appearance of cultures. Colonies on malt extract agar slant $\left(\right.$ at $\left.30^{\circ}\right)$ : growing dense, at first white, becoming gray with sporangia on the upper part of slant; on koji extract agar slant (at $30^{\circ}$ ): turf somewhat dense, covered by small sporangia, becoming dark gray; on Pfeffer-oryzanin agar slant (5) $\left(\right.$ at $\left.30^{\circ}\right)$ : turf somewhat dense or sparse, covered by sporangia, becoming light brownish gray. Sporangiophores simple at first, later becoming branched, with short straight or curved branches racemosely arranged, apically capitate to form vesicles, usually septate, globose, wall rough, $38 \mu \times 29 \mu(11-57 \mu \times 11-56 \mu)$ in diameter. Vesicles covered with abundant projections bearing sporangia without basal cells, globose, ellip- 
tical or irregular in shape, $66 \mu \times 59 \mu(23-120 \mu \times 23-110 \mu)$ in diameter. Sporangia (as termed by $\mathrm{ZYCHA}_{\mathrm{YC}}(6)$ "part-sporangia") at first tubular cells, later septate, containing 3 -spores in a series, readily breakable to spores

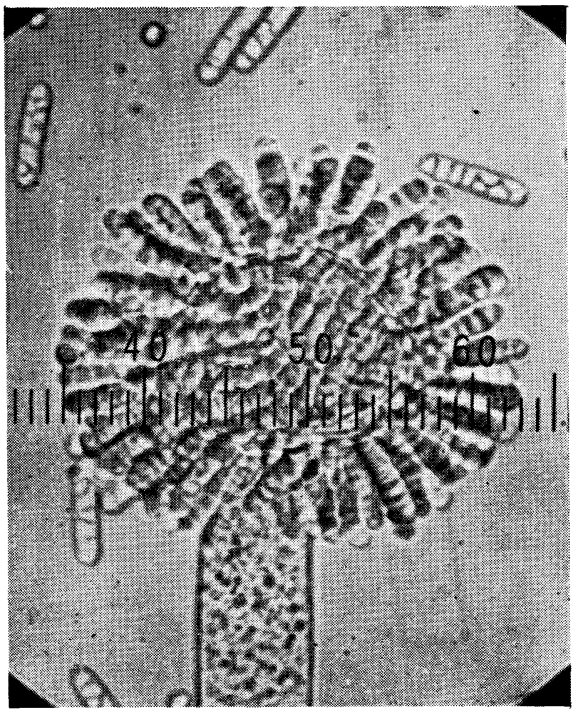

(a)

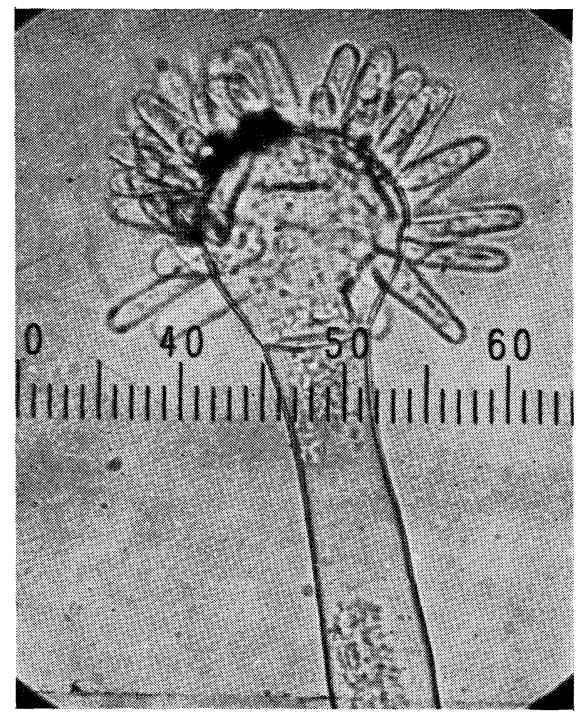

(b)

Fig. 1. Photographs of Syncephalastrum racemosum

in old cultures. Spores globose, elliptical, ovoid, polygonal, rarely cocoonor kidney shaped, or irregular in shape, $4.6 \mu \times 4.2 \mu(2-8 \mu \times 2-6 \mu)$ in diameter. Zygospores and chlamydospores, not observed.

Gas formation from several carbohydrates. On Pfeffer solution containing 5\% glucose, fructose, galactose, sucrose, maltose or starch respectively $\left(\right.$ at $30^{\circ}$ ), wet mycelial mat formed and gas not formed from them (in fermentation test-tubes).

\section{(2) Identification.}

It is obvious that this strain belongs to the order Mucorales according to the fact that its hyphae are non-septate and asexual spores occur in sporangia and are non-motile. Then because of the formation and shape of part-sporangia, it belongs to the sub-order Cephalidaceae (by $Z_{\mathrm{YCHA}}$ ) (6) or Piptocephalidaceae (by BESSEY) (7), furthermore to the genus Syncephalastrum for the absence of basal cells.

The genus Syncephalastrum was classified by $\mathrm{ZYcha}(6)$ in regard to the shape and dimensions of spores, as follows: (i) spores globose, $2.5-5 \mu$ (S. racemosum) and (ii) spores ovoid, $5-8 \mu$ (S. fuliginosum and S. javanicum). According to this key, this strain rejects the latter and almost accords with ZYCHA's (6) description of $S$. racemosum in respect to the dimensions of several organs and the number of spores contained in sporangia, except 
that this strain has not always septa under vesicles. Whereas, the present strain distinctly differs from $S$. nigricans, a synonym of $S$. racemosum, which has only $2-3$ spores in sporangia.

Therefore, this strain is decided as Syncephalastrum racemosum (Cohn) SCHROETER (8).

\section{Oxidation of Progesterone.}

In order to isolate the oxidation products, tank culture was performed with a 501 . stainless fermentation tank. To a medium of 301 . with a composition of $5 \%$ glucose, $2 \%$ peptone, $0.3 \%$ corn steep liguor, 31 . of culture precultivated for 48 hours on a medium of the same composition in a shaking flask was inoculated. After cultivation at $30^{\circ}$ for 24 hours, $30 \mathrm{~g}$.

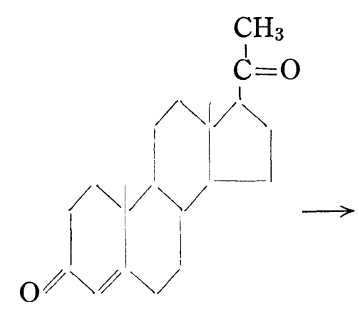

(I)

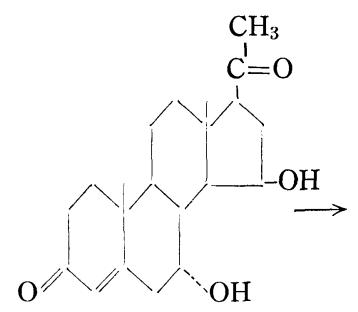

(II)<smiles></smiles>

(III)

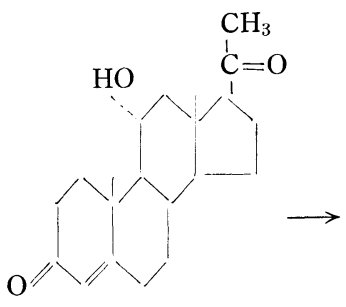

(IV)<smiles>CCC12CC(O)C3C4CCC(=O)C=C4C(O)CC3I1CCC2C(C)=O</smiles>

(V)<smiles>O=C1C=C2CCC3C(CCC4C(C(=O)CO)CCC43)C2CC1</smiles>

(VI)

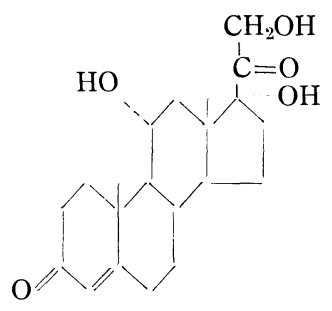

(VII)

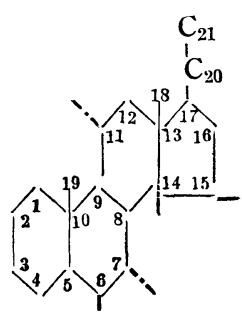

Fig. 2. Hydroxylation of steroids by Syncephalastrum racemosum IAM-6801

(I) progesterone

(II) $7 \alpha, 15 \beta$-dihydroxyprogesterone

(III: $7 \alpha, 14 \alpha, 15 \beta$-trihydroxyprogesterone

(IV) $11 \alpha$-hydroxyprogesterone

(V) 6R, 11 $\alpha$-dihydroxyprogesterone

(VI) Reichstein's compound S

(VII) 11-epihydrocortisone. 
of progesterone dissolved in an amount of $600 \mathrm{ml}$. of methanol was added and fermentation was continued for a further 48 hours (aeration, 301 . per min. (eq. volume), stirring, 250-300 r.p.m.). A comparison of the fermentation course with shake culture in a $500 \mathrm{ml}$. flask is given in Fig. 4. From the figure it was evident that tank fermentation proceeds more rapidly. The entire fermentation course required 72 hours and consumption of sugar in the medium was $93 \%$, being quite satisfactory. After fermentation was completed the culture broth was separated into the mycelium and the filtrate. The mycelum was extracted with acetone, the extract solution and filtrate collected and extracted three times with an equal volume of ethyl acetate. Then the extract solution was evaporated to approx. 21 . and after washing with $2 \%$ sodium bicarbonate solution and distilled water, drying over anhydrous sodium sulfate, the solvent was distilled under reduced pressure, and a residue, $16.5 \mathrm{~g}$., was obtained. Washing with chloroform resulted $5 \mathrm{~g}$. of an insoluble matter. Further treatment with chloroform and consecutive recrystallization from methanol gave needle crystals, $2.3 \mathrm{~g}$, m.p., 262-65 (decomp.) Yield, approx. 7.7\%.

$[\alpha]_{\mathrm{D}}^{28}+103^{\circ}(c=0.5, \mathrm{MeOH})$.

Anal. Calcd. for $\mathrm{C}_{21} \mathrm{H}_{30} \mathrm{O}_{5}$ : C, 69.58, H, 8.34

Found : C, 65.59, H, 8.44

U. V. $\lambda \underset{\max }{\mathrm{MeOH}}: 240.2 \mathrm{~m} \mu(\varepsilon 12,700)$

I. R. $\lambda \underset{\text { max }}{\mathrm{Nujol}}$ : $3,356-3,521(\mathrm{OH}), 1,695(20-\mathrm{CO}), 1,681$ (3-CO), 1,629 $\left(\Delta^{4}\right) \mathrm{cm}^{-1}$

From the above data, the product is considered to be identical with progesterone as it had three hydroxy groups. Studies on the position of the hydroxy groups conducted by TsudA, Oнкі et al (9) gave evidence that this product is $7 \alpha, 14 \alpha, 15 \beta$-trihydroxyprogesterone. A sample of $0.32 \mathrm{~g}$. was dissolved in $2 \mathrm{ml}$. of pyridine, added $2 \mathrm{ml}$. of acetic anhydride and the mixture was allowed to stand overnight. Then, $3 \mathrm{ml}$. of methanol was further added and it was left for a while. Distillation of the solvent under reduced pressure afforded an oily residue, which upon treatment with ether and recrystallization from acetone afforded crystals, m.p. 228-30 .

$[\alpha]_{\mathrm{D}}^{28}+12.6^{\circ}(c=0.62, \mathrm{MeOH})$

Anal. Calcd. for $\mathrm{C}_{23} \mathrm{H}_{32} \mathrm{O}_{6}:$ C, 68.29, H, 7.97

U. V. $\lambda_{\max }^{\mathrm{MeOH}} \quad: 235.7(\varepsilon 15,000)$

Found $\quad: \mathrm{C}, 68.15, \mathrm{H}, 7.97$

I. R. $\lambda_{\max }^{\text {Nujol }} \quad$ : $3,356-3,584(\mathrm{OH}), 1,736(\mathrm{Ac}) 1,692(20-\mathrm{CO}), 1,650(3-\mathrm{CO})$, $1,616\left(\Delta^{4}\right) \mathrm{cm}^{-1}$,

From the above data, the product was confirmed to be a mono-acetate of trihydroxyprogesterone. The chloroform soluble fraction was distilled off and the residue recrystallized from ethyl acetate gave crystals, $5.8 \mathrm{~g}, \mathrm{~m} . \mathrm{p}$., 
$225^{\circ}-226^{\circ}$, identical with $7 \alpha, 15 \beta$-dihydroxyprogesterone previously reported (3). Yield, 19.3\%.

3. Oxidation of $11 \alpha$-progesterone.

After 48 hours' cultivation in the medium described above, $100 \mathrm{mg}$ of $11 \alpha$-hydroxyprogesterone per $100 \mathrm{ml}$. medium dissolved in $2 \mathrm{ml}$. of methanol was added and microbiological oxidation was continued. Consumption of sugar in the medium, mycelial growth and $\mathrm{pH}$ variation almost agreed with data given in Fig. 2 of Part (VI) (3). In this case changes occurring during fermentation were observed to be identical with the case of proges terone used as the substrate. Paper-chromatograms of oxidation productsformed after both 6 and 48 hours' fermentation are given in Fig. 4.

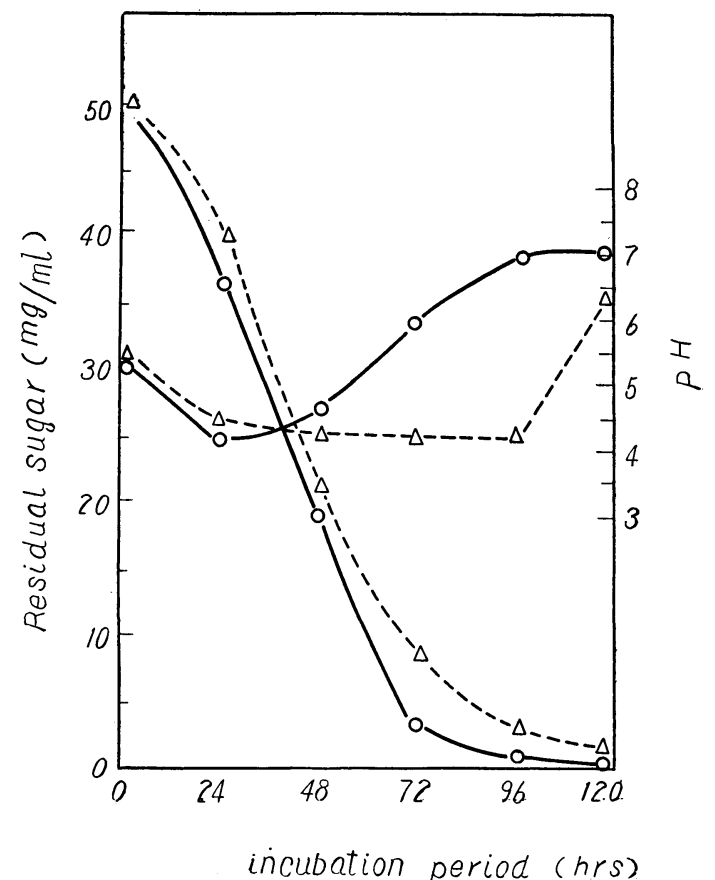

Fig. 3. - $\bigcirc-$ - residual sugar (tank culture)

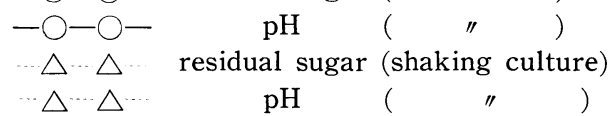

(1) Oxidation products formed after 6 hours' incubation. Two hundred $\mathrm{ml}$. of the medium was extracted with ethyl acetate, evaporated under reduced pressure and two products were obtained from difference of solubility. About $20 \mathrm{mg}$. of the product having lower solubility was obtained and repeated recrystallizations from ethyl acetate afforded crystals. 
Yield, approx. $10 \%$, m.p. $245-7^{\circ}$, mixed melting point with a known $6 \beta$, $11 \alpha$-dihydroxyprogesterone (m.p. $245-48^{\circ}$ ) did not depress.

$[\alpha]_{\mathrm{D}}^{300}+152^{\circ}\left(c=0.97, \mathrm{CHCl}_{3}\right)$,

I. R. $\lambda \underset{\max }{\mathrm{NaOH}}: \quad 3,448(\mathrm{OH}), 1,698(20-\mathrm{CO}), 1,661(3-\mathrm{CO}), 1,618\left(\Delta^{4}\right) \mathrm{cm}^{-1}$

All these data confirmed the product to be identical with $6 \beta, 11 \alpha$-dihydroxyprogesterone. The crystals obtained from the portion readily soluble in ethyl acetate were recrystallized from methanol, m.p. $164^{\circ}$, and confirmed to be identical with $11 \alpha$-hydroxyprogesterone.

(2) Oxidation products obtained after 48 hours' incubation. A culture liquor of $200 \mathrm{ml}$. was extracted with ethyl acetate and treated in the same manner as above. In this case, however, only $6 \beta, 11 \alpha$-dihydroxyprogesterone was obtained. Only a single spot could be detected even when paper chromatography was applied. Yield, $180 \mathrm{mg}$ (approx. 90\%). No substance with three hydroxy groups was produced.

\section{Oxidation of $6 \beta, 11 \alpha$-dihydroxyprogesterone.}

This strain is capable deriving the hydroxygroup into three positions of the structure of progesterone, used as the substrate. For this reason, oxidation by the addition of $6 \beta, 11 \alpha$-dihydroxyprogesterone at growth

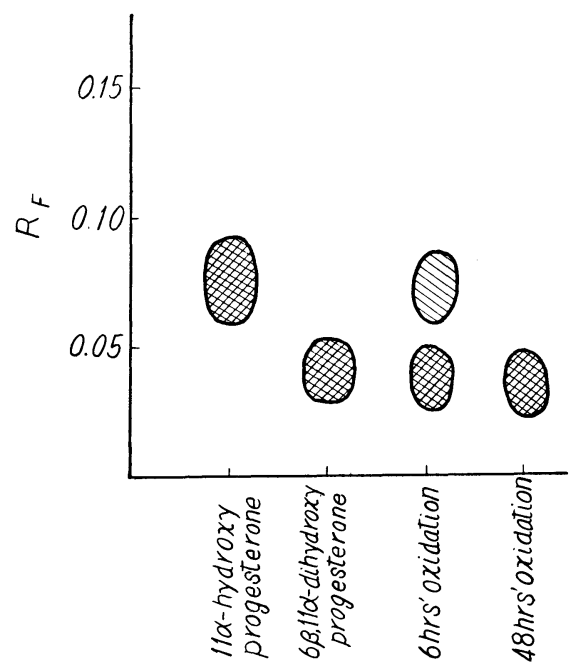

Fig. 4. Oxidation products of $11 \alpha$ hydroxyprogesterone

Solvent: water saturated butanol

Spraying reagent: potassium iodoplatinate

Developed for $16 \mathrm{hrs}$. by Zaffaroni's ascending method. period under highly activate oxidation was attempted. The seed was cultivated for 48 hours after inoculation and $100 \mathrm{mg}$. of $6 \beta, 11 \alpha$ dihydroxyprogesterone (m. p. 205$208^{\circ}$ ) per 100 ml.-medium dissolved in $2 \mathrm{ml}$. of methanol (slightly insoluble) was added, continued to following fermentation for 6 hours and 48 hours, and extrated with ethyl acetate respectively. Although isolation of oxidation products was attempted, only $6 \beta, 11 \alpha$-dihydroxyprogesterone was obtained at each stage. Again in this case, only a single spot could be detected by paperchromatography. From the above results it may be said that when $11 \alpha$-hydroxyprogesterone is employed as the substrate, this strain oxidizes only position 6 , while other positions are not affected. 


\section{Oxidation of Reichstein's Compound S.}

The authors next attempted the oxidation of Reichstein's compound S (11-desoxy, 17-hydroxycorticosterone) which has two hydroxy groups. The procedure was as follows: the strain was cultivated for 48 hours in the medium mentioned above; $100 \mathrm{mg}$ of Reichstein's compound S per $100 \mathrm{ml}$. culture medium dissolved in $2 \mathrm{ml}$. of methanol was then added and microbiological oxidation was continued. At periods of 6 and 48 hours after addition of the substrate, the medium was extracted with ethyl acetate respectively, and the products examined. Paperchromatograms of the oxidation products after 48 hours' incubation are shown in Fig. 5.

(1) Oxidation products formed after 6 hours' incubation.

The extract solution was evaporated and the products examined by paperchromatograpy but no spot expect that of Reichstein's compound S, the substrate could be detected. From the extract solution, crystals, m.p., $198^{\circ}$ were obtained. This crystals did not show depression of melting point on mix melting with Reichstein's compound S.

(2) Oxidation products formed after 48 hours' incubation.

Evaporation of the extract solution gave a crystal, m.p. 208-210. ${ }^{\circ}$ This crystal evidently differed from compound S. For such reason mass culture was performed in order to isolate and identify this product.

(3) Identification of oxidation products.

One hundred $\mathrm{ml}$. of each of the above medium of $10 \mathrm{l}$. was poured into shaking flasks and submitted to mass culture under identical conditions as those described above. Cultivation was performed 48 hours after inoculation of the seed, $100 \mathrm{mg}$. of Reichstein's compound $\mathrm{S}$ per $100 \mathrm{ml}$. medium dissolved in $2 \mathrm{ml}$. of methanol was added and fermentation continued for a further 48 hours. The consumption of Reichstein's com-

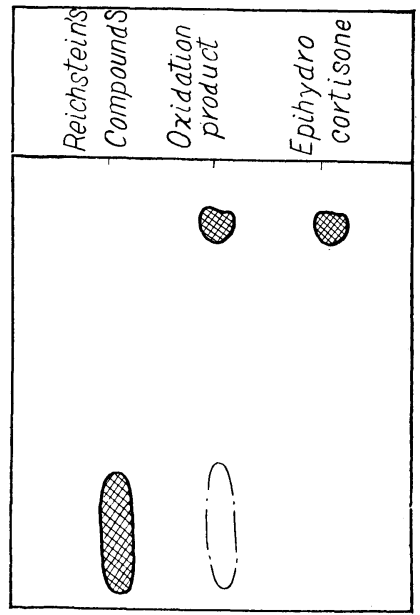

Fig. 5. Oxidation products of Reichstein's Compound S.

Solvent: toluen: dioxan $4: 1$ (saturated with propylen glycol). Tōyō Filter paper treated with a mixture of methanol and propylen glycol (4:6).

Spraying agent: TPTZ Developed for $10 \mathrm{hrs}$ by $Z$ affaroni's descending method pound $\mathrm{S}$ in the medium was $10 \mathrm{~g}$. in total. After cultivation was finished, broth was extracted three times with, ethyl acetate. The ethyl acetate attract was washed with $2 \%$ sodium bicarbonate solution and aq. destilla, dried over anhydrous sodium sulfate and evaporated under reduced pressure. The concentrates were treated with chloroform, and the solvent was evaporated 
under a reduced pressure. The insoluble portion gave $4 \mathrm{~g}$. of solid matter. Recrystallization from acetone afforded the crystals (I), 2.8 g., m.p., 208$210^{\circ}$.

$[\alpha]_{\mathrm{D}}^{16}+107^{\circ}\left(\mathrm{c}=0.73, \mathrm{CHCl}_{3}\right)$

Anal. Calcd. for $\mathrm{C}_{21} \mathrm{H}_{30} \mathrm{O}_{5}:$ C, 69.58, H, 8.35

Found : C, 69.45, H, 8.30

U. V. $\lambda_{\max }^{\mathrm{MeOH}}: 241.4 \mathrm{~m} \mu(\varepsilon 17,800)$

I. R. $\quad \lambda_{\max }^{\text {Nujol }}: \quad 3,497(\mathrm{OH}), 1,706(20-\mathrm{CO}), 1,647(3-\mathrm{CO}), 1,613\left(\Delta^{4}\right) \mathrm{cm}^{-1}$

The infrared spectrum is given in Fig. 6.

From the above data, the product is identical with 11-epihydrocortisone. In order to confirm this result the authors proceeded to prepare derivatives. A quantity of $0.3 \mathrm{~g}$ of the crystals (I) was dissolved in pyridine, added with acetic anhydride and after being allowed to stand overnight, poured onto ice water, extracted with chloroform, recrystallized from a mixture of chloroform-ether. Thus, the crystals (II) an acetylated compound, m.p., $200-202^{\circ}$ was obtained.

$$
[\alpha]_{\mathrm{D}}^{15}+120^{\circ}\left(\mathrm{c}=1, \mathrm{CHCl}_{3}\right)
$$

Anal. Calcd. for $\mathrm{C}_{25} \mathrm{H}_{34} \mathrm{O}_{7}$ : C, 67.24, H, 7.64

Found : C, 67.06, H, 7.74

The above data confirmed this crystal (II) to be a diacetate of 11-epihydroxycortisone.

A portion of $0.2 \mathrm{~g}$. of the crystal (II) was successively dissolved in a solution of water-methanol $(1: 2)$ in which $2 \mathrm{~g}$ of acidic potasium carbonate was dissolved. After being allowed to stand for two days the solution was neutralized with dilute hydrochloric acid, diluted with water, extracted with ethyl acetate, washed with a sodium bicarbonate solution, dried over anhydrous sodium sulfate and the solvent was distilled and recrystallized from a mixture of chloroform-ether. Crystals (III), m.p., 203-5 ${ }^{\circ}$ were obtained.

Anal. Calcd. for $\mathrm{C}_{23} \mathrm{H}_{32} \mathrm{O}_{6}:$
$\begin{aligned} & \text { Found } \\ & \text { : }\end{aligned}$
C, $68.32 \mathrm{H}, 7.32 \mathrm{H}, 7.92$

These date confirmed the product to be a monoacetate of 11-epihydroxycortisone.

A sample of $0.18 \mathrm{~g}$. of the crystals (I) was dissolved in $10 \mathrm{ml}$. of glacial acetic acid, added $5 \mathrm{ml}$. of a solution of $0.43 \mathrm{~g}$. anhydrous chromic acid dissolved in $10 \%$ acetic acid, allowed to stand overnight at room temperature and then diluted. After the neutral fraction was extracted with ether, washed with sodium bicarbonate solution and dried over anhydrous sodium sulfate, the solvent was distilled. A crude crystal was then obtained. purification by alumina column chromatography and recrystallization from a mixture of chloroform-ether gave crystals, 75 g. m.p., 210-212 ${ }^{\circ}$.

Anal. Calcd. for $\mathrm{C}_{19} \mathrm{H}_{24} \mathrm{O}_{3}:$ C, 75.97, H, 8.05

Found $\quad:$ C, $75.68, \mathrm{H}, 8.07$ 
By mix melting point of this crystal with adrenosterone obtained from chromic acid oxidation of cortisone, and comparison of infrared spectrum this crystal was identified to be adrenosterone. Thus, the crystal (1) was confirmed to be 11-epihydrocortisone.

\section{Oxidation of hydrocortisone.}

Hydrocortisone was added as the substrate and the broth was extracted with ethyl acetate at periods of 6 and 48 hours after addition of the substrate. No oxidation products expect the substrate could be found.

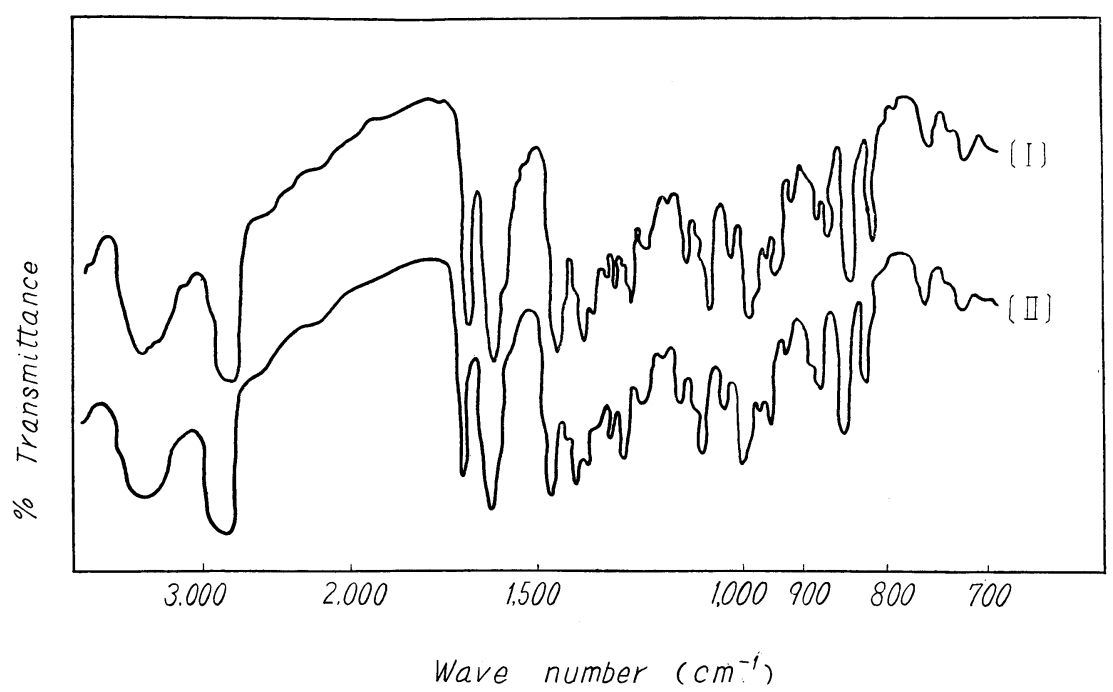

Fig. 6. Infrared spectrum of 11-epihydrocortisone [1] and Reichstein's compound S [II]

\section{DISCUSSION}

From the above experiments conducted with Syncephalastrum racemosum I. A. M. 6801, it is clear that the hydroxy group is induced at five positions of the steroid ring, namely, $6 \beta, 7 \alpha, 11 \alpha, 14 \alpha$, and $15 \beta$. However, in each case, the progress of reaction is dependent on the kind of steroid employed.

This may be elucidated from the fact that progesterone which does not possess a hydroxy group is most readily oxidized - the first product formed being a $7 \alpha, 15 \beta$-dihydroxyl compound and, as oxidation proceeds a $7 \alpha, 14 \alpha$, $15 \beta$-trihydroxyl compound is formed. However, is worthy to note that even in the same progesterone, reaction differs according to the position of the hydroxyl group. As for example, when a certain progesterone with a hydroxy group attached at the $11 \alpha$-position so used as the substrate, an entirely different reaction occurs, offering a $6 \beta$-hydroxyl compound. Moreover, the 
reaction is much more retarded than in the case of progesterone. As for Reichstein's compound S, which still has one more hydroxyl group, oxidation products are not observed in a short period, the production of 11 epihydrocortisone is first recognized only after a long cultivation period. Furthermore, when $6 \beta, 11 \alpha$-dihydroxyprogesterone and hydrocortisone were used as the substrates no any oxidation products were formed.

As it is shown here, a considerable difference in oxidation is due to a slight change in the structure of the steroid substrate. This is certainly a markable characteristic of microbiological oxidation which is also observed in the oxidation of progesterone and 11-desoxycorticosterone (10) by Rhizopus arrhizus, and that of progesterone and $11 \alpha$-hydroxyprogesterone (11) by Calenectria decora.

\section{SUMMARY}

On the strain which was used in the previous report $(2,3)$ and described as Syncephalastrum sp., taxonomical studies were made and it was decided as Syncephalastrum racemosum (Cohn) Schroeter.

This fungus formed $7 \alpha, 15 \beta$-dihydroxyprogesterone from progesterone in a short period of incubation, while $7 \alpha, 14 \alpha, 15 \beta$-trihydroxyprogesterone in a ong period. By this strain, $6 \beta, 11 \alpha$-dihydroxyprogesterone and 11-epihydrocortisone were also formed from $11 \alpha$-hydroxyprogesterone and compound $\mathrm{S}$, respectively. However, no oxidation products could be found from $6 \beta$, $11 \alpha$-dihydroxyprogesterone and hydrocortisone.

\section{ACKNOWLEDGEMENTS}

The authors wish to express their gratitude to Prof. Dr. K. Tsuda and Assoc. Prof. Dr. Inzuka of this Institute for their kind help. Thanks are also given to Dr. H. Okazaki, Mr. R. Shirasaka and Mr. T. Akabori of Sankyo Pharmaceutical Co. Ltd. for the assistance of carring out tank fer. mentation, to Mr. K. Aizawa, Dept. of Agr. Chem., Univ. of Tokyo, for infrared spectral measurements, and to Mr. Y. Sato and Miss. H. Yamano$\mathrm{UCHI}$ of this Institute for elemental analysis.

\section{REFERENCES}

(1) T. Asai, K. Tsuda, K. Aida, E. Ohki, T. Tanaka, M. Hattori and H. MachiDA: J. Gen. Appl. Microbiol., 4 (2) 63 (1958).

(2) T. Asai, K. Aida, E. Ohki, T. Tanaka, and M. Hattori: J. Agr. Chem. Soc. Japan, 32, 723 (1958).

(3) T. Asai, K. Tsuda, K. Aida, E. Ohki, T. Tanaka and M. Hattori: J. Gen. Appl. Microbiol., 4 (2) 79 (1958).

(4) K. Tsuda, T. Asai, E. Ohki, I. Tanaka and M. Hattori: Chem. Pharm. Bull., 6, 387 (1958).

(5) Y. TAKedA: J. Agr. Chem. Soc. Japan. 11, 845 (1935). 
(6) H. ZYCHA: "Kryptogamenflora der Mark Brandenburg" Band VIa, Pilze II, Mucorineae, Leipzig, Gebrüder Borntraeger (1935).

( 7 ) E. A. Bessey: "Morphology and Taxonomy of Fungi”, P. 183, Philadelphia, Blakiston (1952).

(8) J. Schröter: Kryptog. Fl. Schlesien, 3, 1, 217 (1886).

( 9 ) K. Tsuda, T. Asai, E. Ohki, T. Tanaka and T. Matsuhisa: Chem. Pharm. Bull., 7, 369 (1939).

(10) S. H. Eppstein, P. L. Meister, D. H. Peterson, H. C. Murray, H. M. Leigh, D. A. Lyttle, L. M. Reineke and A. Weintraub: J. Am. Chem. Soc., 75, 408 (1953).

(11) A. Schubert, G. Langbein and R. Siebert: Chem. Ber., 90, 2576 (1957). 